\section{International Scientific Journal Theoretical \& Applied Science}

p-ISSN: 2308-4944 (print)

e-ISSN: 2409-0085 (online)

Year: 2015 Issue: 02 Volume: 22
http://www.T-Science.org
Amangeldi Shapievich Khamzin

doctor of Law, professor,

Chairman of the Board of Trustees

Innovative University of Eurasia, Kazakhstan notarius-almaty@rambler.ru

Zhanna Amangeldinovna Khamzina doctor of Law, professor, Kazakh National Pedagogical University named after Abay, Kazakhstan

SECTION 32. Jurisprudence.

\title{
INTERNATIONAL LEGAL MAINTENANCE OF GUARANTEE MECHANISMS FOR SOCIAL AND LABOR RIGHTS
}

\begin{abstract}
The relevance of the work's theme is determined by theoretical undevelopment of the system of international legal fundamentals to ensure social and labor rights in the Republic of Kazakhstan, demand for practical formation and development of Kazakhstan's social and labor legislation on the fundamental basis of generally recognized rules and standards in this sphere. There had been made conclusions that the significance of international social and labor standards is in development of the national law, in its compliance with generally and universally recognized rules; standards serve as determinants in unification and consolidation of the internal legislation, determine level of assurance in social and labor sphere, as well as carry out the function of development of the national law-making; besides, these determinants serve as parameters of internal social policy.

Key words: social and labor sphere, social rights, labor rights, social standards, social protection, social maintenance.
\end{abstract}

Language: Russian

Citation: Khamzin AS, Khamzina ZA (2015) INTERNATIONAL LEGAL MAINTENANCE OF GUARANTEE MECHANISMS FOR SOCIAL AND LABOR RIGHTS. ISJ Theoretical \& Applied Science 02 (22): 65-74. doi: http://dx.doi.org/10.15863/TAS.2015.02.22.12

\section{МЕЖДУНАРОДНО-ПРАВОВОЕ ОБЕСПЕЧЕНИЕ МЕХАНИЗМОВ ГАРАНТИЙ СОЦИАЛЬНЫХ И ТРУДОВЫХ ПРАВ ЧЕЛОВЕКА}

Аннотация: Актуальность темы работы обусловлена теоретической неразработанностью системы международно-правовых основ обеспечения сочиальных и трудовых прав человека в Республике Казахстан, востребованностью практики формирования и развития сочиильно-трудового законодательства Казахстана на фундаментальной базе общепризнанных норм и стандартов в данной сфере. Сделаны выводы о том, что значение международных сочиально-трудовых стандартов заключается в развитии национального права в направлении его соответствия общепризнанным и универсальным нормам; стандарты выполняют роль детерминантов унификации и консолидации внутригосударственного законодательства, определяют уровень гарантий в соииально-трудовой сфере, а также осуществляют функиию развития национального правотворчества; выступают в качестве параметров внутригосударственной социальной политики.

Ключевые слова: социально-трудовая сфера, сочиильные права, трудовые права, соичиальные стандарты, социальная защчита, социильное обеспечение.

Современный глобальный мир предъявляет особые требования к сотрудничеству государств в социально-трудовой сфере, а также к параметрам и механизмам обеспечения прав человека на национальном уровне с учетом соответствующих международных стандартов. «Необходимость тесного конструктивного взаимодействия международной и национальной правовых систем предопределяется общественнополитическими, экономическими и специально- юридическими факторами объективного характера, порождаемыми, среди прочего, процессом глобализации окружающего нас мира. Они обусловливают социально-нормативную общность процессов создания, развития и функционирования указанных нормативных системных конструкций» [1, с. 9].

Международное право является важнейшим источником для формирования внутригосударственного права, правовой основой 
для эффективного сотрудничества стран в различных сферах. Современные процессы глобализации, характеризующиеся развитием экономических, финансовых, научных, культурных и иных социальных связей между странами выводят параметры взаимодействия государств на качественно новый уровень. «Глобализация в качестве характеристики современного цивилизационного процесса представляет собой форму интеграции человечества в целостную систему на базе ценностей западноевропейского гуманизма, идеологически обеспечивающего политикоправовой процесс, протекающий на национальном, региональном и глобальном уровнях» [2, с. 13]. Процессы создания мировых систем безопасности, интеграции государств являются важнейшими предпосылками для выработки общепризнанных стандартов, предъявляемых к закреплению и соблюдению прав человека, механизмам их гарантированности. В данном направлении ведущую роль играет деятельность международных организаций, целями функционирования которых является выработка, закрепление и внедрение международных стандартов прав человека, что имеет своей целью создание стабильных основ безопасности во всем мире.

Одним из важнейших направлений развития сотрудничества государств является социальнотрудовая сфера как область общественных отношений, в которых реализуются основные социальные и трудовые права человека. Особое значение указанное направление взаимодействия государств приобретает в связи с особой ценностью социально-трудовых прав, как естественных прав личности, специфическим значением для признания государства подлинно социальным.

Развитие государства по пути социально организованного предполагает функционирование высокого уровня гарантий социальных и трудовых прав человека, что обеспечивается политическими, правовыми, организационными механизмами, включающими в себя возможности как государственных институтов, так и негосударственных.

Правовое обеспечение социальных и трудовых прав человека осуществляется системой источников национального и международного права, поскольку, «будучи включенными в правовую систему государства, международные нормы действуют как часть этой системы и обеспечиваются присущим ей механизмом. При этом нормы международного права сохраняют свой статус, не теряют своего международно-правового качества, то есть остаются частью международно-правовой системы» [3, с. 77]. Указанное свойство международных норм нами рассматривается как важнейшая особенность международно-правовых основ социально-трудовых прав человека в Республике Казахстан. С одной стороны, международным сообществом выработаны и закреплены базовые параметры социальных и трудовых прав человека, которые являются органической частью международных норм, с другой стороны, акты международного правотворчества, устанавливающие основополагающий перечень и механизмы реализации социально-трудовых прав, являются составным и важнейшим элементом национальной правовой системы.

Правовое обеспечение направлено на формирование системы правовых источников, адекватно отражающих реально существующие те или иные виды общественных отношений. Международно-правовые основы обеспечения социально-трудовых прав человека, по нашему мнению, - это совокупность важнейших основополагающих международных норм, регулирующих базовые устои международных институтов, функционирующих в данной сфере, и международные отношения, направленные на обеспечение, гарантию и реализацию социальнотрудовых прав человека, что дает основание для его выделения в самостоятельный международноправовой институт.

Кроме того, обращение к данной проблеме продиктовано тем фактом, что «Республике Казахстан предстоит пройти длительный, сложный путь для обеспечения эффективной защиты прав человека в соответствии с международным стандартом. Поэтому считать, что наше общество обеспечивает полную реализацию стандартов в области прав человека, на данном этапе было бы преждевременно; если быть объективным, то в этой области решительных успехов все еще мы не достигли. Это объясняется тем, что все происшедшие общественные преобразования за последние годы не были прямо и непосредственно нацелены на развитие гуманитарной сферы общества. Задачи по обеспечению эффективной защиты прав человека отодвигались на второй план по сравнению с задачами, связанными с решением экономических, социальных и политических проблем общества» [4, с. 83].

Категория «социально-трудовые права» нами выбрана для обозначения всего комплекса социальных и трудовых прав человека, исходя из их общей природы, близости субъектного состава, взаимосвязи и взаимообусловленности.

Трудовые и социальные права человека имеют конституционный уровень гарантированности и 
закрепления. Конституция РК в силу своего специфического качества основного законодательного акта страны, определяющего в юридической форме характеристику государства, его цели и задачи, закрепляет формы реализации гражданами своих способностей к трудовой деятельности.

Конституция провозглашает равенство и невозможность ограничения прав граждан (в том числе и в сфере созидательной деятельности) независимо от пола, расы, национальности, происхождения, отношения к религии, убеждений, принадлежности к общественным объединениям и т.д. (ст. 14).Отличительной чертой Конституции РК 1995 года является то, что государство отказалось от декларативного провозглашения абсолютного права граждан на труд в том смысле, как это понималось в Конституции СССР. На современном этапе государство, не имея экономических возможностей, не в состоянии гарантировать реализацию названного права. Исходя из конституционных положений государство лишь принимает на себя обязанность осуществлять деятельность, направленную на создание условий, обеспечивающих достойную жизнь и свободное развитие человека. Формы же обеспечения могут быть самыми различными: создание организационно-правовых условий для различных форм реализации способности к труду (предпринимательства, работы по трудовому договору, государственной службы и др.), выплата пособий по безработице и т.д. [5, с. 540]. Согласно статье 24 Конституции, в Республике Казахстан каждый имеет право на условия труда, отвечающие требованиям безопасности и гигиены, на вознаграждение за труд без какойлибо дискриминации, а также на социальную защиту от безработицы.

Признается право на индивидуальные и коллективные трудовые споры с использованием установленных законом способов их разрешения, включая право на забастовку.

Каждый имеет право на отдых. Работающим по трудовому договору гарантируются установленные законом продолжительность рабочего времени, выходные и праздничные дни, оплачиваемый ежегодный отпуск.

В соответствии со статьей 28 Конституции гражданину Республики Казахстан гарантируется минимальный размер заработной платы и пенсии, специальное обеспечение по возрасту, в случае болезни, инвалидности, потери кормильца и по иным законным основаниям.

Конституция Республики Казахстан закрепляет право на свободу объединений (статья 23), право на свободу предпринимательской деятельности (статья 26), право на охрану здоровья (статья 29), равное право на доступ к государственной службе (статья 33).

В соответствии со статьей 28 Конституции гражданину Республики Казахстан гарантируется минимальный размер пенсии, социальное обеспечение по возрасту, в случае болезни, инвалидности, потери кормильца и по иным законным основаниям. Поощряются добровольное социальное страхование, создание дополнительных форм социального обеспечения и благотворительность.

Право на социальное обеспечение как неотъемлемое естественное право человека имеет место в связи с наступлением определенной жизненной ситуации, с которой закон связывает возникновение субъективного права у лица требовать от правообязанного субъекта предоставления того или иного вида социального обеспечения. Конституция Республики Казахстан в ст. 28 устанавливает лишь минимальный перечень социальных фактов, в связи с наступлением которых гарантируется предоставление социального обеспечения, - это возраст, инвалидность, потеря кормильца, перечень иных оснований устанавливается законами республики.

Конституция Республики Казахстан закрепляет еще ряд социальных прав: это право на жилище указанным в законе категориям граждан, нуждающимся в жилье, которое согласно пункту 2 статьи 35 Конституции РК предоставляется за доступную плату из государственных жилищных фондов в соответствии с установленными законом нормами, право на бесплатное образование (статья 30), на охрану здоровья, которое предполагает предоставление бесплатного гарантированного объема медицинской помощи. Перечисленные права относятся к социальным в широком понимании как связанные с социальной сферой жизнедеятельности общества. Однако узкий взгляд, взятый за основу определения границ научного анализа, позволяет нам отнести к социальным правам личности право на социальное обеспечение, право на гарантированный минимальный уровень социального обеспечения, право на социальную помощь, социальное обслуживание, участие в системе социального страхования и страховые выплаты, то есть все те правомочия личности, обеспечиваемые системой социальной защиты населения.

Социально-трудовые права человека имеют естественную природу. В правовой теории понятие, означающее совокупность принципов, правил, прав и ценностей, продиктованных самой природой человека и в силу этого не зависящих от законодательного признания или непризнания 
их в конкретном государстве. Согласно теории права естественное право возникло задолго до появления государства и может существовать без него.

Вместе с тем, реальные гарантии права на свободу труда, материального обеспечения социальной защиты населения могут существовать только при государственном устройстве общества, прежде всего это связано с созданием и закреплением государственных механизмов обеспечения человеку возможности трудиться в условиях, отвечающих требованиям охраны труда, получать достойное вознаграждение, финансирования мер социальной защиты. Таким образом, действенные возможности и инструменты реализации социально-трудовых прав возможны только в рамках государственных институтов, но как правовая категория социально-трудовые права не связаны с возможностью государства их предоставить, гарантировать. Право на достойный, достаточный уровень жизни принадлежит каждому от рождения, лица, находящиеся в трудной жизненной ситуации (потеря кормильца, работы, болезнь, инвалидность и многое другое), имеют право на бесплатный объем гарантированной медицинской помощи, на оплату труда не ниже минимального размера, человек имеет естественное право на жилище.

Общепризнанные мировым сообществом требования к состоянию и развитию сферы использования наемного труда, социального обеспечения, защиты, помощи и обслуживания содержатся в различных международных актах, к которым относятся: Копенгагенская декларация о социальном развитии (принята Всемирной встречей на высшем уровне в интересах социального развития, Копенгаген, 6-12 марта 1995 года), Стандартные Правила Организации Объединенных Наций «Об обеспечении равных возможностей для инвалидов» (Нью-Йорк, 20 декабря 1993 года), Резолюция тринадцатой сессии Генеральной Ассамблеи Организации Объединенных Наций 3447(XXX) «Декларация о правах инвалидов» от 9 декабря 1975 г., Декларация Организации Объединенных Наций «О социальном прогрессе и развитии» (11 декабря 1969 года, принята 11.12.1969 Резолюцией 2542 (XXIV) на 1829-м пленарном заседании Генеральной Ассамблеи ООН), Конвенция Международной организации труда № 157 «Об установлении международной системы сохранения прав в области социального обеспечения» (Женева, 21 июня 1982 г.), Конвенция Международной организации труда № 128 «О пособиях по инвалидности, по старости и по случаю потери кормильца» (Женева, 29 июня 1967 г.), Конвенция Международной организации труда № 118 «О равноправии граждан страны и иностранцев и лиц без гражданства в области социального обеспечения (Женева, 6 июня 1962 г.), Конвенция Международной организации труда № 103 «Об охране материнства» (пересмотренная в 1952 году) (Женева, 4 июня 1952 г.), Конвенция Международной организации труда № 102 «О минимальных нормах социального обеспечения» (Женева, 4 июня 1952 г.), Конвенция Международной организации труда № 48 «Об установлении системы международного сотрудничества по сохранению прав, вытекающих из страхования по инвалидности, старости и на случай потери кормильца семьи» (Женева, 4 июня 1935 г.), Европейская социальная хартия (Страсбург, 3 мая 1996 г.), Хартия социальных прав и гарантий граждан независимых государств (утв. Межпарламентской Ассамблеей государств-участников Содружества Независимых Государств 29 октября 1994 г.) и др.

Международные социально-трудовые нормы являются, как правило, более прогрессивными относительно внутреннего законодательства и носят характер минимальных социальнотрудовых стандартов, к соблюдению которых должны стремиться государства. Таким образом, базовое значение международных социальнотрудовых стандартов заключается в развитии внутринационального права в направлении его соответствия общепризнанным и универсальным нормам.

Учитывая специфику Казахстана, на основе международного опыта при рассмотрении институциональной базы системы социальной защиты предпочтение было отдано смешанной системе, при которой эффективно используются возможности как государственных, так и частных институтов, именно в данном направлении осуществляется современное развитие социальной сферы Республики Казахстан.

Значение международных стандартов в социальной сфере заключается в том, что их положения являются основой для построения систем соответствующего законодательства. При этом следует иметь в виду, что развитость институтов в данной области отношений в том или ином обществе зависит, прежде всего, от состояния экономики, финансовых возможностей государства, наличия достаточных средств для охвата всех нуждающихся в социальной поддержке, обеспечении занятости населения. Перечень категорий нуждающихся в социальной поддержке граждан также прямо зависим от экономических возможностей государства, 
исторических предпосылок, векторов проводимой социальной государственной политики, а также степени имплементации международных стандартов в данной сфере в национальное законодательство. В связи с чем верно отмечается в научно-практических источниках о том, что социально-трудовое законодательство как своего рода интегрированная отраслевая система покоится, во-первых, на конституционных нормах, вовторых, на международно-правовых актах, принимаемых и действующих в социальной сфере [6, с. 2-3].

Международные социально-трудовые стандарты становятся своего рода параметрами развития внутригосударственной социальной политики. Социальное развитие непосредственно влияет на рост экономики, обеспечение государственной безопасности. Социальная политика является составной частью государственной политики государства. Еe субъектами являются государственные органы всех уровней. Партнерами государственных структур по реализации социальной политики призваны стать международные, неправительственные общественные и другие организации.

Характерной чертой современного государственного управления является возрастающая тенденция к перераспределению ролей среди субъектов осуществления государственной социальной функции, с сохранением доминирующей роли государственного управления в реализации мер и мероприятий, предусмотренных параметрами социальной политики. Учитывая специфику Казахстана, на основе международного опыта при рассмотрении институциональной базы системы социальной защиты предпочтение, полагаем, должно быть отдано смешанной системе, при которой эффективно используются возможности как государственных, так и частных институтов.

Одним из перспективных направлений внедрения международных стандартов в механизмы обеспечения социально-трудовых прав человека, полагаем, является нормативное закрепление стандартов социальной деятельности негосударственных организаций (некоммерческих и коммерческих) в данной сфере. Современные требования к реализации социально ориентированной деятельности государства заключаются в ее осуществлении совместно институтами власти и общественными негосударственными институтами, данные требования в Республике Казахстан находятся на начальных этапах обеспечения: создается надлежащая нормативная правовая база, внедряются формы взаимодействия государственных и негосударственных методов в регулировании соответствующих общественных отношений. Вместе с тем полагаем, что объективным процессом является преобладание государственных механизмов обеспечения гарантий социально-трудовых прав человека, что является следствием значительной финансовой зависимости соответствующей сферы общественных отношений от государственных источников финансирования, которые обладают статусом гарантированных, что определяет именно государственные механизмы в реализации социальных мероприятий в качестве приоритетных. Возможности общественных негосударственных структур могут дополнять социальную деятельность структур публичной власти в организационном аспекте.

Социальная политика государства основывается на общепринятых принципах и нормах международного права и международных договорах государства, его Основном законе и иных нормативных правовых актах.

Международные стандарты становятся ориентирами для внедрения новых базовых принципов упорядочивающего воздействия на социально-трудовую сферу, пересмотра роли государства и работодателей, представителей бизнеса в социально-трудовых отношениях. Эффективная деятельность государства в данной сфере является одним из условий успешной реализации экономической, политической и других государственных функций. На современном этапе развития Республики Казахстан субъекты рыночных экономических отношений активно вовлекаются в обеспечение социальной ориентации казахстанской экономики и создание развитого, адекватно отражающего состояние общества и потребности его граждан социального законодательства. Более того, полагаем, заинтересованными государственными органами совместно с представителями бизнессообщества должны быть разработаны национальные стандарты социальной ответственности бизнеса. В данном направлении начата деятельность: принят Государственный стандарт Республики Казахстан «Социальная ответственность. Требования» СТ РК 1352-2005 (SA 8000:2001, MOD), область применения которого ограничена требованиями к социальной ответственности организации независимо от форм собственности, в рамках социальнотрудовых правоотношений, возникающих непосредственно в рамках отдельных организаций, учреждений, предприятий, являющихся работодателями, использующими в своей деятельности наемный труд. 
Таким образом, в современных условиях международные социально-трудовые стандарты ответственности бизнес структур за состояние социально-трудовой сферы являются одними из векторов развития организационного, правового обеспечения условий существования данной области общественных отношений, более того, определяются государственной властью в качестве ориентиров проведения соответствующей национальной политики.

На современном этапе проведения социальных реформ в Республике Казахстан главными задачами государственной власти становятся создание эффективной системы защиты трудовых прав работников, социального обеспечения, достижение социальной справедливости, которые обеспечиваются механизмом государственных социальных гарантий.

Решающее значение для реализации социальных гарантий, закрепленных в Конституции Республики Казахстан, приобретает формирование и использование социальных стандартов, норм и нормативов на республиканском и местном уровнях социальной защиты населения. Социальная стандартизация является новой сферой регламентации важнейших параметров социального развития со стороны органов государственной власти, органов местного самоуправления в условиях рыночных отношений.

Анализ современного социального законодательства показывает, что в настоящее время государство осуществляет деятельность по определению социальных стандартов в форме разработки уровня прожиточного минимума и приведения под его величины, а также соотнесение с ним всех видов социальных выплат, осуществляемых за счет средств республиканского и местных бюджетов. Показанное положение вещей представляется искусственным сужением понятия социальных стандартов, а также роли государства в управлении социальной сферой, что приводит к искажению определения и реализации государственной социальной политики, значительному снижению эффективности механизмов реализации гарантий конституционных социальных прав граждан. На наш взгляд, общий перечень социальных прав человека в широком значении, охватываемых конституционными гарантиями, включает в себя:

- право на социальное обеспечение по возрасту в случае болезни, инвалидности, потери кормильца и по иным законным основаниям, обеспечение права на минимальный размер пенсии (статья 28 Конституции РК);
- право на гарантированное статьей 30 Конституции РК бесплатное образование;

- право на создание условий для обеспечения граждан жильем, на предоставление жилища указанным в законе категориям граждан, нуждающимся в жилье, за доступную плату из государственных жилищных фондов в соответствии с установленными законом нормами (статья 25 Конституции РК);

- право на охрану здоровья (статья 29 Конституции РК).

Выделение социальных прав и понимание необходимости государственного управления сферой их реализации выводит проблему определения социальных стандартов их предоставления на первый план при определении всей социальной политики, целей и задач государства в этой сфере. Полагаем, изложенное достаточно аргументирует приоритетность и жизненную необходимость разработки и применения в Республике Казахстан социальных стандартов как основных механизмов конституционных гарантий социальных и трудовых прав.

Базовая разработка социальных стандартов, применяемых при построении национального законодательства, проведении государственной социальной политики осуществляется специализированными международными органами и организациями, общепризнанными мировым сообществом. Ведущая роль в данном направлении деятельности принадлежит ООН и еe институтам, занимающимся вопросами развития Программы Развития ООН (ПРООН). ПРООН содействует разработке и реализации национальных стратегий развития, продвижению демократических и экономических реформ, укреплению институционального и человеческого потенциала. ПРООН осуществляет проекты в различных регионах Казахстана, помогая смягчить негативное воздействие переходного периода на жизни людей. ПРООН предоставляет консультационные услуги, реализует проекты на местах и выпускает публикации по различным аспектам развития страны. Ее работа в Казахстане сосредоточена в следующих трех сферах:

- снижение бедности,

- демократическое управление,

- окружающая среда и устойчивое развитие.

Активное и эффективное участие Казахстана в ПРООН является одним из важнейших каналов проникновения международных социальнотрудовых стандартов во все сферы общественных отношений, определяя параметры развития соответствующего законодательства.

Кроме того, значительна роль Международной организации труда в 
имплементации общепризнанных социальнотрудовых стандартов в правовую систему Казахстана, которая осуществляется по нескольким направлениям:

- включение актов МОТ в систему законодательства, путем выражения Казахстаном согласия на обязательность для него международного договора посредством подписания договора, обмена документами, ратификации договора, его принятия, утверждения, присоединения к договору либо любым другим способом, о котором условились договаривающиеся стороны;

- разработка и реализация стратегических программ сотрудничества между Казахстаном и MOT.

Таким образом, международные социальнотрудовые стандарты становятся частью национальной правовой системы и социальнотрудовой сферы общественных отношений и соответствующей ей области государственного управления, используя различные механизмы внедрения. В современных условиях Республики Казахстан социально-трудовые стандарты становятся новыми параметрами оценки качества реализации социально-трудовых прав человека, их введение позволит более полно учитывать интересы граждан, общества и государства в социальной сфере, обеспечивать эффективность развития Казахстана как социального государства.

На наш взгляд, социальным стандартам следует определять минимально необходимый уровень обеспечения социальных гарантий, выражаемых в важнейших социальных нормах, установленных законодательством. Система социальных стандартов должна формироваться на основе необходимых гарантий реализации социальных прав и не должна ограничиваться сферой социального обеспечения, обслуживания. Сфера социального нормирования шире, она должна включать в себя наиболее важные, обобщающие и долговременные социальные показатели. К основным типам минимальных социальных стандартов считаем целесообразно отнести:

- прожиточный минимум;

- минимальные доходы в виде минимального размера оплаты труда и пенсий из солидарной системы и базовые пенсионные выплаты;

- минимальные размеры социальных пособий и выплат;

- номенклатуру, перечни и наборы бесплатных и частично платных общедоступных услуг, оказываемых населению за счет финансирования из бюджетной системы Республики Казахстан;
- минимальные размеры социальных страховых выплат;

- минимальный уровень пенсионного обеспечения за счет добровольных и добровольных профессиональных пенсионных накоплений;

- перечни категорий населения, имеющих право на оказание социальной помощи;

стандарты необходимого уровня содержательного наполнения, требований и технологий предоставления социальных услуг; нормы обеспечения населения социальными услугами и соответствующими учреждениями;

нормы кадрового, материальнотехнического и другого обеспечения учреждений социального обслуживания населения;

- нормы предоставления доступного жилья, в том числе стандарты инфраструктурного наполнения социального строительства для приоритетных категорий граждан;

- нормы предоставления гражданам страховых выплат при наступлении социальных рисков в рамках добровольного социального страхования.

Считаем, что введение и построение в Республике Казахстан системы социальных стандартов позволит значительно повысить эффективность социальной политики. Данный механизм в полной мере позволит реализоваться основному принципу адресности в предоставлении мер по социальной защите и социальной справедливости.

Указанные характеристики правового и организационного обеспечения социальнотрудовой сферы являются одними из ориентиров проведения современных социальных реформ, государственной социальной политики в Республике Казахстан. Вместе с тем, полагаем, на сегодняшний день в качестве основного приоритета для Казахстана в данной сфере должно стать приближение величины прожиточного минимума к общемировым стандартам по содержанию и денежному выражению, поскольку именно данный показатель выполняет в современных условиях роль индикатора и основной величины, с которой соотносятся и на которую ориентирован уровень минимальной заработной платы, пенсионного обеспечения, социальных пособий.

Данное направление деятельности, на наш взгляд, должно в себя включать:

- расширение перечня параметров, составляющих продовольственную корзину, в соответствии с общепризнанными стандартами полноценного питания человека, с учетом особенностей требований к сбалансированному питанию в Казахстане. «В основе показателя 
прожиточного минимума находится продуктовая корзина, которая содержит научно обоснованную ценность пищевого рациона. Если сравнить этот показатель в странах СНГ, где он составляет 2100-2500 ккал на человека в сутки, и в США, где этот показатель значительно выше - 3700 ккал, то можно установить разницу в уровне жизни населения этих стран» [7, с. 20];

- разработка на основании научного обоснования и законодательное закрепление стоимостного выражения расходов на непродовольственные товары и услуги, которые в совокупности с продовольственной корзиной составляют в натуральном и стоимостном выражении прожиточный минимум. В современных условиях Республики Казахстан непродовольственные расходы определяются произвольно, научно не обоснованы и не соответствуют параметрам и целям своего применения в величине прожиточного минимума. Согласно Пункту 8 Правил расчета величины прожиточного минимума [8], стоимость продовольственной корзины рассчитывается уполномоченным государственным органом по статистике путем умножения научно обоснованных физиологических норм потребления продуктов питания, входящих в продовольственную корзину для различных половозрастных групп населения, на средние цены регистрации в представительных объектах розничной торговой сети по состоянию на середину текущего месяца в городе республиканского значения, столице, областных и районных центрах. Доля продовольственной корзины составляет $60 \%$ стоимости прожиточного минимума.

Соответственно

стоимость непродовольственных товаров и услуг составляет $40 \%$ от прожиточного минимума. Таким образом, непродовольственная часть минимума ни научно, ни практически законодателем не обоснована, рассчитывается от величины продовольственной корзины, которая не имеет ничего общего с непродовольственными товарами и услугами. Указанная правовая ситуация требует своего разрешения, грамотного и всестороннего подхода специалистов разноотраслевой направленности и установления научно обоснованной и объективной величины прожиточного минимума в Республике Казахстан.

Одним из направлений решения поставленной проблемы, полагаем, может стать введение наряду с понятием прожиточного минимума категории минимального потребительского бюджета. «Если прожиточный минимум определяет, в первую очередь, физиологические потребности человека, то минимальный потребительский бюджет нацелен на удовлетворение социальных потребностей человека, поэтому размер его в несколько раз выше размера прожиточного минимума. Именно этот показатель должен быть ориентиром для определения минимальных зарплат, пенсий, пособий, стипендий и других социальных выплат. Потребительская корзина как основа минимального потребительского бюджета отличается от страны к стране не только методами, которыми она рассчитывается, но и составом. К примеру, в США потребительская корзина включает 300 наименований товаров и услуг, во Франции - 250, в Великобритании 350, Германии - 475» [7, с. 20-21];

- законодательное закрепление величины черты бедности в Республике Казахстан. Черта бедности в соответствии с Законом «О прожиточном минимуме» устанавливается в зависимости от экономических возможностей государства и служит критерием для оказания социальной помощи малообеспеченным гражданам. Размер черты бедности определяется ежеквартально в процентах от прожиточного минимума Министерством здравоохранения и социального развития Республики Казахстан. Социальное значение черты бедности заключается в наделении правом населения, чей доход ниже данного параметра, претендовать на получение адресной социальной помощи в виде денежных выплат за счет средств местных бюджетов. Размер черты бедности определяется Министерством самостоятельно, произвольно, без соответствующей правовой и научной аргументации. Данная функция центрального уполномоченного органа неоднократно подвергалась критике со стороны депутатов Парламента РК [9]. Следует подчеркнуть, что на сегодняшний день данная проблема не нашла своего адекватного разрешения, в казахстанском законодательстве отсутствуют обоснованные механизмы и параметры определения черты бедности;

- в соответствии с международными стандартами нуждается в корректировке понятие «черта бедности» и «прожиточный минимум» в аспекте соответствия в денежном выражении двух приведенных величин. Безусловно, категории «черта бедности» и «прожиточный минимум» имеют различное смысловое и социальное значение. Естественно, что удовлетворение (в денежном выражении) минимальных потребностей человека, то есть черта бедности, должно соответствовать стоимости минимальной потребительской корзины, то есть прожиточному минимуму, доход ниже потребительской корзины не обеспечивает самого физического существования 
человека, не может обеспечить его жизнедеятельность.

Концепция базовых потребностей, $\begin{array}{llll}\text { появившаяся в } & \text { в } & \text { годах }\end{array}$ $\mathrm{XX}$ столетия в исследовательских кругах в Скандинавии, легла в 1976 году в основу доклада Международной организации труда «Занятость, рост и базовые нужды».

Суть этой концепции заключается в том, что она предлагает правительствам строить экономическую и социальную политику в расчете на: а) обязательное удовлетворение некоторых минимальных потребностей семьи в пище, одежде, жилище и домашнем имуществе; б) улучшение общественных услуг в области обеспечения питьевой водой, санитарного состояния мест проживания, общественного транспорта, здравоохранения и образования.

МOT, а следом за ней и другие организации, входящие в систему ООН, увязывают удовлетворение этих потребностей с соблюдением прав человека и считают важнейшим условием достижения целей концепции «базовых нужд» раскрепощение инициативы людей, вовлечение их в «развитие через участие» как на уровне принятия решений, так и на уровне их практического воплощения.

Согласно статье 25 Всемирной декларации прав человека, каждый человек имеет право на такой жизненный уровень, включая пищу, одежду, жилище, медицинский уход и необходимое социальное обслуживание, который необходим для поддержания здоровья и благосостояния его самого и его семьи, право на обеспечение на случай безработицы, болезни, инвалидности, вдовства, наступления старости или иного случая утраты средств к существованию по независящим от него обстоятельствам» [10].

Таким образом, международные стандарты в социально-трудовой сфере не только расширяют содержание прожиточного минимума, но и связывают их исполнение государствами с созданием гарантий реализации социальных прав человека на достаточный с точки зрения базовых потребностей человека уровень жизни в случае утраты трудоспособности за счет социальных выплат, а при вступлении в трудовые отношения - за счет оплаты труда. Международные социальные стандарты обязывают государства рассматривать бедность в точки зрения доходов на уровне и ниже прожиточного минимума и предполагают предоставление в данной ситуации гарантированной государством социальной поддержки населения.

Следует отметить, что исполнение социальных обязательств является для Республики Казахстан важнейшим приоритетом в любых финансово-экономических условиях. События последнего этапа развития, произошедшие в мировом масштабе кризисного финансово-экономического характера, не могли не затронуть Республику Казахстан как интегрированного члена мирового сообщества. Однако негативные последствия в виде существенного сокращения доходной части государственного бюджета не повлекли снижение уровня выполняемых государством социальных обязательств.

Полагаем, что одним из важнейших направлений в развитии социально-трудовых отношений должно стать внедрение международных стандартов обеспечения социально-трудовых прав человека в Республике Казахстан. В данном направлении предстоит провести большую аналитическую работу по систематизации и анализу действующего внутреннего законодательства на предмет его соответствия: во-первых, закрепления международных стандартов социально-трудовых прав человека; во-вторых, соответствия в содержательном и материальном выражении объема и размера предоставляемых форм социальной защиты и соответствующих требований общепризнанных стандартов.

Данное направление совершенствования законотворческого процесса, на наш взгляд, окажет положительное воздействие на процесс исполнения Республикой Казахстан взятых на себя международных социальных обязательств, позволит более качественно осуществлять внедрение и непосредственное применение международных норм. Требуется обязательное научное прогнозирование последствий принятия нормативных правовых актов в социальнотрудовой сфере с точки зрения социальных экономических, политических и иных аспектов. Нуждается в качественном изучении с точки зрения потребностей имплементации во внутреннее право международных социальнотрудовых стандартов, в отношении которых республика уже выразила свое согласие, а итогом данной деятельности должно стать создание эффективного, отвечающего требованиям международных общепризнанных норм, социального и трудового права Республики Казахстан. 


\section{References:}

1. Gavrilov VV (2006) International and national legal systems: the concept and main areas of cooperation: Author. dis. ... dr. jurid. sciences. Kazan, 2006.

2. Romanova LM (2009) National sovereignty in the context of globalization: the institutional and legal analysis: Author. dis. ... dr. jurid. sciences. Rostov-on-Don, 2009.

3. Matveeva TD (2008) International law: Lectures. Moscow: Publishing House "RAGS", 2008.

4. Sabikenov SN (2005) Problems of the relationship between international and domestic law in the area of human rights / Bulletin of the al-Farabi. A series of international relations and international law. 2005. № 1 (17).

5. (1996) Course of Russian labor law. General part / Ed. EB Khokhlov. St. Petersburg: Publishing, St. Petersburg University/ 1996. In 3 t. T. 1.

6. (2005) Social legislation: Scientific and practical guide / Tikhomirov Y.A. Moscow: The Law Firm "Contract": INFRA-M, 2005.
7. Babaeva LY (2009) Poverty and social policy in the Republic of Tajikistan: Author. dis. ... doctor of philosophy. sciences. Dushanbe/ 2009.

8. (2005) Rules for calculating the subsistence minimum. Approved by the joint order of Acting Minister of Labour and Social Protection of the Republic of Kazakhstan dated December 2, 2005 № 307/1-p and the President of the Republic of Kazakhstan Agency on Statistics of December 5, 2005. № 194.

9. (2015) The poverty line. Available: http://www.zonakz.net/articles/2940 (Accessed: 20.02.15).

10. Shokamanov JK (2012) Analysis of Poverty in Kazakhstan: global problems, national and regional peculiarities. Newsletter number 4, "The problem of poverty in the context of social policy in the Republic of Kazakhstan. Astana, 2012. Available: http://www.undp.kz/projects/files/11830507.htm (Accessed: 20.02.15). 